\title{
RESEARCH ON SHORTENING TIME WITHOUT AFFECTING THE ACCURACY OF DYER'S IMODIFIED IMETHOD FOR THE DETERIMINATION IN SOILS, OF PHOSPHORIC ACID, LIME AND POTASH SOLUBLE IN CITRIC ACID SOLUTION (1 PER CENT)
}

\author{
Juan Amedée Bonnet, Chief of Soils Division, \\ Fernando A. Villamil, Soil Chemist, \\ Insular Experiment Station, Río Piedras, P. R.
}

Since the soil survey of Puerto Rico started in 1928 under the joint cooperation of the U. S. Bureau of Chemistry and Soils and the P. R. Insular Experiment Station, the soil samples sent by the field staff have been analyzed for phosphoric acid, lime and potash soluple in 1 per cent citric acid solution. Before this research was undertaken as one of the projects of the new Soils Division officially created in June 1931, the method used was as follows:

\section{Dyer's Modified Method}

"Place 100 grams of the air dried soil sample in a Winchester acid bottle. Add 1 liter of a 1 per cent citric acid solution. Shake in a shaking machine 6 hours. Let stand overnight to clear. Filter off about 700 ee of the clear supernatant liquid through a double filter paper. Evaporate exactly 500 ec nearly to dryness in a $600 \mathrm{ce}$ beaker on the hot plate, then transfer the resulting dark colored solution to a platinum dish (using hot water) and evaporate to dryness on a water bath. Completely dry the sticky residue (2 hours in a hot air oven at a temperature of about $120^{\circ}$ C.).

"Ignite the residue in the platinum dish in a muffle at low temperature (dull redness) for about 2 hours to remove organic matter. The char should now be gray in color. Moist with con. HCl, add a little hot water and evaporate to dryness on the water bath. Leave on water bath at least 1 hour to dehydrate any silicic acid still remaining as such. Take up in a little con. $\mathrm{HCl}$; add a little water; heat one-half hour on a water bath; add more hot water and filter. Wash five times with hot water slightly acidified with $\mathrm{HCl}$; make up to at least $300 \mathrm{ce}$ with hot water. To the clear filtrate add 2 or $3 \mathrm{ce}$ of con. $\mathrm{HNO}_{3}$ and boil 15 to 20 minutes to oxidize all organic matter in solution. Precipitate $\mathrm{Fe}, \mathrm{Al}$, Ti and $\mathrm{P}_{2} \mathrm{O}_{5}$ with $\mathrm{NH}_{4} \mathrm{OH}$ in 
hot solution, filter and wash free from chlorides with hot water. In case of insufficient $\mathrm{Fe}$ to color the solution slightly brown, add a few ec of a 10 per cent $\mathrm{FeCl}_{3}$ solution before precipitation. (This is to insure complete ppt. of $\mathrm{P}_{2} \mathrm{O}_{5}$.)

\section{Phosphoric Acid, $\mathrm{P}_{2} \mathrm{O}_{5}$}

"Dissolve the above ppt. in dil. $\mathrm{HNO}_{3}$ and boil. Cool slightly, nearly neutralize with $\mathrm{NH}_{4} \mathrm{OH}$ add 5 grm. $\mathrm{NH}_{4} \mathrm{NO}_{3}$ and ppt. $\mathrm{P}_{2} \mathrm{O}_{5}$ with $25 \mathrm{cc}$ molybdate sol. at $65^{\circ} \mathrm{C}$. Let stand $20 \mathrm{~min}$. at $65^{\circ}$ then let cool. Filter through asbestos, thoroughly wash and det. $\mathrm{P}_{2} \mathrm{O}_{5}$ volumetrically.

\section{Lime, $\mathrm{CaO}$}

"Evaporate down to 150 ec the filtrate from $\mathrm{Fe}$ and A1, make very slightly alkaline with $\mathrm{NH}_{4} \mathrm{OH}$ and ppt. Ca as oxalate with ammonium oxalate in hot solution. Let stand on the water bath 1 hour then cool over night. Filter, wash with cold water, dissolve in $\mathrm{H}_{2} \mathrm{SO}_{4}$ ( 1 to 5 by vol.) and titrate with a standard $\mathrm{KMnO}_{4}$.

\section{Potash, $\mathrm{K}_{2} \mathrm{O}$}

"Acidify filtrate from Ca slightly with dil. $\mathrm{H}_{2} \mathrm{SO}_{4}$. Evaporate to dryness in a beaker, transfer to platinum dish and run to dryness. Carefully ignite off excess of $\mathrm{H}_{2} \mathrm{SO}_{4}$ and all ammonium salts over a free flame; take up residue with hot water, filter into porcelain evap. dish and add 2 or 3 drops of dil. $\mathrm{HCl}$ and sufficient platinic chloride sol. to ppt. all the potassium. Evaporate nearly to dryness, filter, wash and weigh as potassium platinic chloride in the usual gravimetric way."

\section{EXPERIMENTAL}

The modified procedures introduced have been as follows:

Place 150 grams of the air dried soil sample in a Winchester acid bottle. Add $1500 \mathrm{cc}$ of a 1 per cent citric acid solution. Shake in a shaking machine, 6 hours. Let stand overnight to clear. Filter.

\section{Phosphoric Acid, $\mathrm{P}_{2} \mathrm{O}_{5}$}

Measure in a beaker, 500 ce of the filtered citric acid extract. Add $10 \mathrm{cc} \mathrm{HNO}_{3}$ and $30 \mathrm{cc} \mathrm{HCl}$. Evaporate in hot plate, nearly to dryness. Transfer to evaporating dish and dry residue carefully, in sand bath. Ignite the residue at low temperature to destroy the un- 
decomposed organic matter and complete the dehydration and destruction of silicates. Dissolve in $5 \mathrm{ce} \mathrm{HNO}_{3}$ and $15 \mathrm{ce} \mathrm{HCl}$, dilute with water and filter. Follow official molbydate volumetric method. (If a brown color due to manganese persists in the solution after neutralizing with $\mathrm{NH}_{4} \mathrm{OH}$ and acidifying with $\mathrm{HNO}_{3}$, heat to coagulate the colloidal suspension and filter.)

\section{Lime, $\mathrm{CaO}$}

Measure in a beaker, 100 ec of the filtered citric acid extract. Determine lime by Chapman's (4) method as follows:

To the solution containing $\mathrm{Ca}, \mathrm{Mg}, \mathrm{Mn}, \mathrm{Fe}, \mathrm{Al}, \mathrm{Ti}$, and $\mathrm{P}_{2} \mathrm{O}_{5}$ add about 6 grams of $\mathrm{NH}_{4} \mathrm{Cl}$. One gram of oxalic acid in solution, 10 ce of 1.76 normal acetic acid, and 10 drops of .04 per cent brom cresol green, are added. The solution is made to a volume of about 200 ce and brought nearly to boiling. Dilute ammonia is added slowly until a drop of the solution added to a drop of brom cresol green in a porcelain spot plate changes from yellow thru yellowish green to the first pure green (pH3.9-4.2). The solution is then boiled gently for five minutes, the calcium precipitating in a coarse erystalline state. The precipitate is then allowed to stand on a steam bath until it wholly subsides. Allow the solution to cool before filtration. Wash five times with cold water. Determine CaO by the official permanganate volumetric method.

\section{Potash, $\mathrm{K}_{2} \mathrm{O}$}

Evaporate $500 \mathrm{ec}$ of the filtered extract nearly to dryness, on the hot plate. Transfer the resulting dark colored solution to a silica dish (using hot water) and carefully evaporate to dryness on a sand bath. Ignite the residue in a muffle to about $1000^{\circ} \mathrm{F}$. (incipient red heat) for about 2 hours to remove organic matter. Add $15 \mathrm{cc} \mathrm{HCl}$, add a little hot water and evaporate to dryness on the water bath. Take up in 5 ec of $\mathrm{HCl}$ and water, heat for 30 minutes on a water bath; add more hot water and filter. Wash three times with hot water and make up to about $200 \mathrm{ce}$. To the clear filtrate add $2 \mathrm{ce}$ of $\mathrm{HNO}_{3}$ and boil 10 minutes to oxidize all organic matter in solution. In hot solution, precipitate $\mathrm{Fe}, \mathrm{Al}$, Ti and $\mathrm{P}_{2} \mathrm{O}_{5}$ with $\mathrm{NH}_{4} \mathrm{OH}$ adding also $25 \mathrm{ce}$ of saturated ammonium oxalate solution to precipitate $\mathrm{Ca}$ and Mg. Filter and wash well with hot water. (In case of insufficient Fe to color the solution slightly brown, add a few ce of a 10 per cent $\mathrm{FeCl}_{3}$ solution before precipitation. This is to insure complete precipitation of $\mathrm{P}_{2} \mathrm{O}_{5}$.) 
To filtrate add $2 \mathrm{ce} \mathrm{H}_{2} \mathrm{SO}_{4}(1: 1)$ and evaporate to dryness in sand bath. (It is convenient to add $5 \mathrm{cc}$ of $\mathrm{HNO}_{3}$ before evaporating to dryness to avoid losses due to the creeping out of the salts.) Ignite to whiteness to expel ammonium salts. Extract with hot water and filter. Determine $\mathrm{K}_{2} \mathrm{O}$ by the official Lindo-Cladding method.

\section{Analyticat Results of Percenty CaO by Chapman's Method}

Comparative values by Student's method of percent $\mathrm{CaO}$ as determined by Dyer's modified and Chapman's methods are expressed in table I. To eliminate personal error, all analyses by both methods were performed in the same extraction by the same chemist, F. A. Villamil. The letters A or B following a sample number represent duplicate extractions. The values in columns $\mathrm{A}$ and $\mathrm{B}$ represent percent $\mathrm{CaO}$ obtained respectively, by the Dyer modified method and by the Chapman method. The values of column (A-B) are obtained by subtracting the values of column $B$ from those of $A$. The factor .9702 was obtained by dividing the total of column $\mathrm{A}$ by that of $\mathrm{B}$. The values of column $\mathrm{C}$ are obtained by multiplying that factor by the values of column $B$. The values of column $(A-C)$ are obtained by subtracting the values of column $C$ from those of $A$. The values $\mathrm{D}$ and $\mathrm{D}^{1}$ represent mean deviations. The standard deviation of the mean of column $(\mathrm{A}-\mathrm{B})$ is obtained by the formula:

$$
\text { S. D. }=\sqrt{\frac{\mathrm{SmD}^{2}}{\mathrm{n}(\mathrm{n}-1)}}
$$

where $\mathrm{SmD}^{2}$ is the sum of the values $\mathrm{D}^{2}$ and $\mathrm{n}$, the number of observations. The standard deviation of the mean of column $(\mathrm{A}-\mathrm{C})$ is obtained by that same formula substituting $\operatorname{Sm}\left(D^{1}\right)^{2}$ for $S \mathrm{SD}^{2}$.

The value $Z$ represents the ratio of the mean of column (A-B) to the square root of the mean of the values $D^{2}$. The value $\left(Z^{1}\right)$ represents the ratio of the mean of column $(A-C)$ to the square root of the mean of the values $\left(D^{1}\right)^{2}$. The statistical interpretation of the results was obtained with values $Z$ and $n$ in the Student's table modified by Love (9), $\mathrm{n}=91$ in this case. 
TABIE I.

COMPARATIVE VALUES BY STUDENT'S AETHOD OF PERCENT CAO AS DETERMINED BY DYER'S MODIFIE] AND CHAPMAN'S METHODS.

\begin{tabular}{|c|c|c|c|c|c|c|c|c|c|}
\hline No. & $\begin{array}{l}\text { Dyer's } \\
\stackrel{A}{\mathrm{CaO}}\end{array}$ & 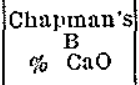 & $A-B$ & $\stackrel{D}{(A-B+.014)}$ & $D^{3}$ & $\begin{array}{c}\mathrm{C} \\
(y 702 \mathrm{~B})\end{array}$ & $A \rightarrow C$ & 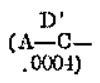 & $\left(\mathrm{U}^{\prime}\right)^{2}$ \\
\hline 1 & 260 & .288 & .022 & -.008 & .000064 & .279 & -.013 & -.0134 & .00017056 \\
\hline$\frac{1}{2}$ & .697 & .781 & -.034 & -020 & .000400 & .709 & -.012 & -.0124 & .00015376 \\
\hline 3 & 241 & $.261)$ & -.019 & -.005 & .020025 & .252 & -.011 & -.0114 & .00012996 \\
\hline 4 & .118 & .126 & -.008 & .006 & .000086 & .122 & & $-.004 i$ & .00001936 \\
\hline 5 & .034 & .118 & -.034 & -.020 & $.000-100$ & .114 & -.030 & -.0304 & .00092416 \\
\hline 0 & .051 & .664 & -.013 & .001 & .600001 & .062 & -.011 & -0114 & .00012996 \\
\hline 7 & .518 & .529 & -.011 & .003 & .000000 & .513 & .005 & .0046 & .00002116 \\
\hline 8 & .065 & .070 & -.005 & .009 & .000081 & .068 & -.003 & -.0094 & .00001156 \\
\hline 9 & .081 & .095 & -.014 & 0 & 0 & .002 & -.011 & -.0114 & .00012996 \\
\hline 10 & .868 & .958 & -.090 & -.076 & .005776 & .929 & -.061 & -.0614 & .00276996 \\
\hline 11 & .110 & .137 & -.027 & -.013 & .000109 & 133 & -.028 & -.0234 & $.0005+756$ \\
\hline 12 & $.08 \bar{\imath}$ & .098 & -.011 & .003 & . 6004013 & .095 & -.008 & $-\cos 1$ & .00007050 \\
\hline 13 & .378 & .403 & -.025 & -0.011 & .000121 & .391 & -.013 & -0134 & .00017956 \\
\hline 14 &, 079 & .084 & -.005 & .009 & .000081 & .081 & -.002 & -0024 & - 00000576 \\
\hline 15 & .171 & .168 & .008 & .011 & .010289 & .163 & .008 & $: 0076$ & .00005776 \\
\hline 16 & .266 & .314 & -.048 & -.034 & .001156 & .305 & -.039 & -0394 & .00155236 \\
\hline 17 & .952 & .960 & -.008 & .006 & .000086 & .931 & .021 & .0206 & .00042436 \\
\hline 18 & $.55 \overline{4}$ & .596 & -.042 & -.028 & .000784 & .578 & -.024 & -.0244 & .00059586 \\
\hline 19 & .137 & .151 & -.014 & 0 & 0 & .147 & $=.010$ & -.0104 & -00010816 \\
\hline 20 & .120 & .154 & -.025 & -.011 & .000121 & .149 & $=020$ & -0204 & - Co041616 \\
\hline 21 & .224 & .238 & -014 & 0 & 0 & .231 & $=007$ & .0074 & -00005476 \\
\hline 22 & .756 & .795 & -.039 & -.025 & $.00 \times 0625$ & $.7 \pi 1$ & $=.015$ & -0154 & -00023716 \\
\hline 23 & $.28 \%$ & .305 & -.019 & -.005 & .000025 & .296 & -.010 & $-\mathrm{u} 104$ & - 00010816 \\
\hline 24 & .244 & .252 & -.008 & .006 & .000036 & .244 & 0 & -0004 & - 00000016 \\
\hline 25 & .594 & .605 & -.011 & .003 & .000009 & .587 & .007 & ${ }^{\circ} 0006$ & $\cdot 00004356$ \\
\hline 26 & .532 & & -.014 & 0 & u & .530 & .002 & .0016 & -10000256 \\
\hline 27 & .644 & 650 & -.606 & .008 & .000064 & .631 & .013 & $\cdot 0126$ & . 00415876 \\
\hline 28 & $.48 \bar{i}$ & $50-1$ & -.017 & .003 & .000009 & .489 & .002 & -.0024 & - 00100576 \\
\hline 29 & .616 & 622 & .006 & .008 & .0 .50464 & - 6013 & .013 & $\cdot 0126$ & .00015876 \\
\hline 30 & .305 & 314 & -009 & .005 & .000025 & .305 & -0 & -.0004 & $.000000 \div 6$ \\
\hline $31 \Lambda$ & .164 & .067 &,- 003 & .011 & .000121 & .065 & $=.001$ & -.0014 & - o0roo196 \\
\hline $3 \perp B$ & .001 & .067 & -.003 & .011 & .000121 & .065 & -.001 & -.0014 & - coor:0196 \\
\hline 32 & .599 & .602 & -.003 & .011 & .010121 & .584 & .015 & .0146 & $\cdot 00021316$ \\
\hline 38 & .160 & .165 & -.005 & .009 & .000081 & .160 & 0 & -.0004 & -00000016 \\
\hline 34 & .132 & .134 & -.002 & .012 & .000144 & .130 & 002 & .0016 & $\cdot 00000256$ \\
\hline 35 & .269 & .274 & -.005 & .009 & .000081 & 266 & .003 & .0026 & - 05000676 \\
\hline 36 & 1.310 & 1.330 & -.020 & -.006 & .000080 & 1.290 & .020 & .0196 & .00038416 \\
\hline 37 & .089 & .087 & .004 & .016 & .000256 & .081 & .005 & .10 .46 & .000012116 \\
\hline $38 \mathrm{~A}$ & .092 & 700 & -.008 & .000 & .000036 & .679 & .013 & $.01 \leqslant 6$ & $.000158 \pi 6$ \\
\hline 3813 & .694 & .708 & -.009 & .005 & .000025 & , 682 & . 012 & .0116 & - 0013456 \\
\hline $39 \mathrm{~A}$ & .691 & 683 & .011 & .025 & .000625 & .668 & .031 & .0306 & . 00093636 \\
\hline $39 \mathrm{~B}$ & .689 & .680 & .003 & .017 & .60259 & .666 & .023 & .0226 & - C0051076 \\
\hline $40 \mathrm{~A}$ & .014 & .647 & -.008 & .011 & .000121 & .628 & .016 & .0156 & -10024336 \\
\hline $40 \mathrm{~B}$ & .641 & +652 & -.011 & .003 & .000109 & .633 & .008 & .0076 & .00005756 \\
\hline & .549 & .534 & -.005 & .009 & .000081 & .587 & .012 & .0116 & .00013456 \\
\hline $41 B$ & .548 & 548 & -.005 &, 009 & .000081 & .532 & .011 & .0106 & 1236 \\
\hline $42 \mathrm{~A}$ & +106 & .246 & -.050 & -.080 & .501296 & .239 & -.018 & -.0434 & .00188356 \\
\hline $42 \mathrm{~B}$ & .196 & 241 & -.0 .15 & -.031 & .000301 & .234 & $=088$ & -.0381 & .00147456 \\
\hline $43 \mathrm{~A}$ & .410 & .448 & -.008 & .006 & .000026 & .435 & $.00 \overline{5}$ & .0046 & .00002116 \\
\hline $43 B$ & 428 & 454 & -.026 & -.01 & .000144 & .410 & -.012 & -.0124 & .00015876 \\
\hline $44 \mathrm{~A}$ & .336 & .303 & -.017 & -.003 & .000009 & .342 & -.006 & -.0064 & .00001096 \\
\hline $44 \mathrm{~B}$ & .353 & .358 & -.005 & .009 & .000081 & .847 & .006 & .0056 & .00003186 \\
\hline $45 \mathrm{~A}$ & 2.128 & 2.134 & -.006 & .008 & $.00000 \mathrm{i}$ & 2.07 & .058 & $.05 \% 6$ & .00331776 \\
\hline & 2.122 & 2.139 & -.017 & -.003 & .000009 & 2.075 & .047 & .0466 & .00217156 \\
\hline & .428 & .437 & -.009 & .005 & .000025 & .424 & .004 & & .00001296 \\
\hline & .423 & . 496 & -.003 & .011 & .0 .0121 & .413 & .010 & .0090 & .00009216 \\
\hline 47. & .230 & .246 & $-\mathrm{cll}$ & .009 & .000009 & .299 & -.004 & -.0044 & .00010280 \\
\hline 47 & .234 & .235 & $\cdots .011$ & .003 & .000004 & .228 & -.004 & -.0044 & .00001936 \\
\hline $48 \mathrm{~A}$ & .303 & .3356 & -.00 & .01 & .000 & .326 & .007 & & $.000043 \tilde{6} 6$ \\
\hline & .383 & .326 & -.003 & .011 & .000121 & .326 & .00 & .0056 & .00004356 \\
\hline $49 \mathrm{~A}$ & .126 & .154 & -.028 & -.014 & .000106 & .149 & -.029 & -.0234 & .00054756 \\
\hline & .107 & .119 & .009 & -.023 & .00529 & .144 & .013 & $=.0126$ & .00015876 \\
\hline กิด & 700 & $\pi 06$ & -.006 & $\infty$ & .000061 & .685 & .016 & .0146 & .00021316 \\
\hline 51 & 655 & 700 & -045 & -.031 & .000961 & .679 & -.024 & -.0244 & .00059536 \\
\hline 52 & & 888 & -.028 & -.009 & .000081 & .862 & .003 & .0026 & .00000676 \\
\hline 53 & 784 & .792 & -.008 & .006 & .000036 & .76 & .016 & .0156 & .000243336 \\
\hline 54 & 1.123 & 1.212 & -089 & -.075 & .015625 & 1.176 & -.053 & -.0534 & .00285156 \\
\hline $5 \overline{5}$ & .073 & .064 & 009 & 1123 & 000529 & .062 & 011 & $0: 06$ & OC011236 \\
\hline 56 & .081 & 095 & -.014 & 0 & 0 & .092 & -.011 & -0114 & .00012996 \\
\hline 57 & .591 & 599 & -008 & .006 & .000086 & .581 & 010 & $\cos 6$ & .00009216 \\
\hline & $.69 t$ & 602 & -.008 & .006 & .000036 & .584 & $011)$ & .0096 & .00009216 \\
\hline & .40 & 412 & or & .008 & .000064 & 400 & .006 & 0056 & .00003136 \\
\hline & & & & .006 & .000036 & .415 & .005 & .0046 & .00002116 \\
\hline
\end{tabular}


TABLE 1 .

COMPARATIVE VALUES BY STUdent's METHOD OF PERCENT CAO AS DETERMINED BY DYER'S MODIFIED AND CHAPMAN'S METHODS-Continued.

\begin{tabular}{|c|c|c|c|c|c|c|c|c|c|}
\hline No. & $\begin{array}{l}\text { Dyer's } \\
\% \stackrel{\Lambda}{\mathrm{C} 4 \mathrm{O}}\end{array}$ & $\begin{array}{c}\text { Chapmans } \\
\text { B } \\
\text { \% }{ }^{\mathrm{CaO}}\end{array}$ & $A-B$ & $\stackrel{\mathrm{D}}{(\mathrm{A}-\mathrm{B}+.014)}$ & $\mathrm{D}^{2}$ & $\underset{(.9702 \mathrm{~B})}{\mathrm{C}}$ & $A-C$ & $\begin{array}{l}\stackrel{\mathrm{D}^{\prime}}{(\mathrm{A}-\mathrm{C}-\mathrm{C}-} \\
.0004-1\end{array}$ & $\left(D^{\prime}\right)^{2}$ \\
\hline $59 A$ & 409 & .412 & -.003 & .011 & .000121 & 400 & .009 & & \\
\hline & & & .003 & .011 & & .397 & & & \\
\hline & & .1 & 8 & .006 & & .187 & -.002 & -.0 & \\
\hline & & .1 & & .0 & & .18 & -.003 & -.0 & \\
\hline & & & & & & & 010 & & \\
\hline & & & -.00 & .011 & & & .010 & & \\
\hline & & & & 0 & & & .004 & & \\
\hline & & & & .017 & & 1 & .007 & & \\
\hline & 078 & 2.1 & -.08 & -.016 & & 2.0 & .033 & & \\
\hline & 2.0 & 2.108 & -.0 & -.016 & & 2.045 & .033 & & \\
\hline & & & -0 & -.009 & & .101 & -.020 & .02 & \\
\hline & & & -.01 & -.003 & & 10 & -.014 & -.0 & \\
\hline & & & -.01 & .003 & & 1 & -.007 & -.0 & \\
\hline & & 1 & -.002 & .012 & & $1:$ & .002 & 0 & \\
\hline & & & -.006 & .008 & .000 & .1 & 0 & $-\infty$ & \\
\hline & & & -.008 & .006 & .000036 & 3 & .003 & .00 & \\
\hline & .070 & .070 & 0 & 0 & 0 & .068 & .002 & .0016 & .00000256 \\
\hline & 110 & .110 & & & 0 & $11-4$ & & .0036 & .00001296 \\
\hline Sum. & 40.752 & 42.005 & -1.253 & & .025531 & 40.748 & .001 & & .0080778 \\
\hline Mean & .448 & .462 & -.014 & & .00028 & & .0004 & & .00024 \\
\hline
\end{tabular}

$$
\mathrm{Z}=\frac{.014}{\sqrt{.00028}}=.82
$$

Odds over 9999:1

$$
z=\frac{.0004}{\sqrt{.00034}}=.022
$$

Odds below 2:1

When both methods are statistically compared, $\mathrm{Z}=.82$ and the odds from the table (9) are found to be over 9999:1. The odds indicate a real difference in the analytical results between the two methods; since according to the table odds over 21:1 indicate a significant difference in the results.

The evidence suggests that Chapman's method tends to give higher results with a mean deviation of .014 per cent \pm .0017 per cent in 91 determinations or values that may fluctuate between .0123 per cent and .0157 per cent. For comparison purposes the results obtained by either method may be considered entirely satisfactory. That either is as good as the other is corroborated by the excellent checks obtained by each method in the duplicate of different extractions for samples $31,38-49$ inclusive, and 57-64 inclusive. The statistical interpretation, therefore, does not invalidate at all, Chapman's method.

Chances for personal analytical error are much less in the Chapman method since the work is greatly facilitated by the elimination of the cumbersome procedure required for the precipitation of $\mathrm{Al}$, Ti, and $\mathrm{P}_{2} \mathrm{O}_{5}$ with $\mathrm{NH}_{4} \mathrm{OH}$ in the Dyer modified method. The former method saves about 66 per cent of the time required by the latter.

Were it necessary to convert results obtained by Chapman's 
method to those in terms of the Dyer modified method, it would be proper to multiply by the factor .9702 . The value $\mathrm{Z}^{1}$, after the application of such a factor to each result obtained by Chapman's meth. od becomes .022 , and the odds from the table are found to be below $2: 1$. The odds indicate that there is no significant difference between the analytical results of both methods. Results indicate that the increase by Chapman's method tends to be constant. The mean deviation becomes now, .0004 per cent \pm .0017 per cent or a fluctuation between -.0013 per cent and .0021 per cent which is extremely low.

\section{Colormatertc Methods for Phosphoric Acid}

Studies were made of the molybdate blue method with the modifications of Briggs and Doisy applied by Arrhenius (1) to citric acid extracts. The method is as follows:

"Ten ce of the citric acid extract are placed in a $100 \mathrm{ce}$ volumetric flask and diluted to about $80 \mathrm{cc} ; 1 \mathrm{ce}$ con. $\mathrm{H}_{2} \mathrm{SO}_{4}, 5 \mathrm{cc}$ ammonium molybdate ( 25 gms. ammonium molybdate dissolved in 300 ce. water) and then 200 ec dilute sulphuric acid (75 ce conc. $\mathrm{H}_{2} \mathrm{SO}_{4}$ filled up to $200 \mathrm{ce}$ with water), $1 \mathrm{cc}$ sodium sulphite $\left(20 \mathrm{~g} . \mathrm{Na}_{2} \mathrm{SO}_{3}+80 \mathrm{cc}\right.$ water), and $1 \mathrm{ce}$ hydroquinone ( $0.5 \mathrm{~g}$. per $100 \mathrm{ce}$ and one drop conc. sulphuric acid), are added. The flask is filled to the mark and the solution shaken. The color is, after 12 to 24 hours, compared with a standard series of solutions with known $\mathrm{P}_{2} \mathrm{O}_{5}$ content varying between .05 and $.90 \mathrm{mgm} . \mathrm{P}_{2} \mathrm{O}_{5}$ per 100 ce." The so-called Arrhenius molybdate blue method for $\mathrm{P}_{2} \mathrm{O}_{5}$ determinations in eitric acid extract is based on the one recommended by Bell-Doisy-Briggs (2) for $\mathrm{P}_{2} \mathrm{O}_{5}$ determinations in urine and blood, with the exception that the addition of trichloracetic acid for the precipitation of protein material is eliminated.

Although Arrhenius claims that results obtained are accurate below $0.50 \mathrm{mgm} . \mathrm{P}_{2} \mathrm{O}_{5}$ (.05 per cent $\mathrm{P}_{2} \mathrm{O}_{5}$ in the $10 \mathrm{cc}$ citric acid aliquot used by us), our results were entirely inconsistent. The citrate ion colored by the presence of iron salts causes difficulty in matching the color's of the unknown and the standard in the colorimeter.

Studies were made of the method that Warren and Pugh (11) worked out at the Rothamsted Experimental Station based on the colorimetric determination of phosphoric acid in eitric acid extractions of soils as follows:

"Seventy-five ce of the eitric acid extract are pipetted into a 300 ce Kjeldahl flask, $10 \mathrm{ce}$ conc. $\mathrm{HCl}$ added and followed by $12 \mathrm{ce}$ of 20 per cent sodium permanganate. The sides of the flask are washed 
down with a little water. After standing half an hour the contents are vigorously digested till no manganese precipitate remains (about $1 / 2 \mathrm{hr}$. more). The contents are transferred with a minimum amount of water to a $100 \mathrm{cc}$ graduated flask; $4 \mathrm{cc}$ of 10 per cent potassium ferrocyanide are added slowly, drop by drop, with frequent shaking. Several minutes later the mixture is titrated with $1: 1$ ammonia until the blue color just turns purple; 1.5 ce $2 \mathrm{~N}$ sulphuric acid are then added and made to the mark with water. After the solution has been filtered and the first few ce discarded, the color is developed in an aliquot by one of the following methods :

Fiske-Subbarrow (6) "10 to 50 ce are pipetted into a 100 ce graduated flask, diluted to $75 \mathrm{ce}$ approximately, $10 \mathrm{ce}$ of ammonium molybdate added, then $4 \mathrm{cc}$ aminonaphthol sulphonic acid solution and the liquid made to the mark. The flask should be shaken during each addition. The contents are finally ponred into a 100 ec conical flask; 15 minutes later the test compared with a standard phosphate solution".

Deniges (5) - " 1 to 25 ce are pipetted into a $100 \mathrm{ce}$ graduated flask, diluted to $90 \mathrm{ce}$, and $1 \mathrm{ec}$ ammonium molybdate and three drops of stannous chloride solution added, the flask being shaken with each addition. After diluting to the mark the contents are poured into a $100 \mathrm{ce}$ conical flask, and compared after 5 minutes with a standard phosplate solution".

Our results with the Warren and Pugh method were extremely low compared with those obtained by the usual Dyer method. This may be due to the adsorption of phosphates by the manganese ferrocyanide precipitate. Ward (10) states that "the ferrocyanide precipitate is difficult to filter, because of its colloidal condition and that the amount of phosphorous present in the sodium permanganate is of the same order of magnitude as that in the sample, and inaccurate results are certain to follow in the case of soils low in $\mathrm{P}_{2} \mathrm{O}_{5}$ ".

Lonstein (8) applied the method of Deniges, so widely used for water extracts, to eitric acid extracts of a number of South African soils and obtained good agreement with the gravimetric method. His method briefly consists in evaporating a small volume of the citric acid extract to dryness after the addition of calcium acetate solution. The residue is ignited to destroy the organic matter and to render the silica insoluble, and then extracted with 10 per cent sulphuric acid. After filtration the excess of the acid is neutralized with ammonia and the color developed with ammonium molybdate and stannous chloride solutions.

Although we were favorably impressed by the Lonstein method we disregarded it because the figures obtained with it by Warren and Pugh (11) "reveal the presence of some disturbing factor in the analyses of the heavier soils used, especially when the Deniges method 
of color production was used. The blue color developed slowly and had a green tint. The view was sustained that the sulphuric acid extracts from the elay soils contained appreciable amounts of ferric iron as the interfering constituents".

One of the latest contributions to the subject on the colorimetric determination of phosphorus in citric acid extracts of soils is the work of Ward (10), chemist of the Experiment Station of the Hawaiian Sugar Planters' Association. Ward's procedure for the preparation of the eitric acid extract is as follows: "To $100 \mathrm{ml}$. of citric acid extract, add $50 \mathrm{ml}$. of concentrated nitric acid, $15 \mathrm{ml}$. of concentrated hydrochloric acid, and $10 \mathrm{ml}$. of 20 per cent sulfuric acid free from phosphorus and arsenic. Evaporate slowly till fumes of $\mathrm{SO}_{3}$ are evolved. Take up in hot water and boil". The iron is removed by electrodialysis into a special electrolytic cell. The color is developed by the method of Zinzadze as follows: "Aliquots from the solutions of eitric acid extract prepared for analysis are neutralized to the yellow end point of alpha-dinitrophenol indicator with 10 per cent ammonia solution. Dilute the solutions to $90 \mathrm{ml}$., add $1.4 \mathrm{ml}$. of molybdenum blue reagent (molybdic acid reduced by molybdenum metal in sulphuric acid solution), heat for 30 minutes on the steam bath, cool, and make up to exactly $100 \mathrm{ml}$. Employ a sensitive colorimeter for comparison with the standard solution".

The work of different investigators reveal that the accurate colorimetric determinations of phosphoric acid in soils extracted with 1 per cent eitric acid, demands attention on the destruction of the citrate ion, and of the soluble silicates and organic matter; the absence of large amounts of silica; the absence of phosphorous in the chemical reagents used; the elimination of the ferric ion; and a controlled acidity. Ward (10) calls the attention to the presence of titanium and to the use of colorimetric standards which are very close to the unknown in color intensity so as to reduce errors due to deviations from Beer's (12) law.

\section{Treatrients of the Chrric Acid Extracts For the Phosphoric ACID Determinations}

In view of the several difficulties that we encountered in obtaining accurate results with the application of colorimetric methods for the determinations of phosphoric acid in soils extracted with 1 per cent citric acid we proceeded to study the simplification of the chemical treatments given to such extracts in the Dyer modified method and then followed the official molybdate volumetric method for phosphoric acid. 
Our first attempt was to precipitate directly phosphoric acid as ammonium phosphomolybdate in aliquots of the citric acid extracts. In some cases, good checks were obtained with the results by the Dyer modified method. In other cases, no precipitate was obtained; and in other cases, lower results were obtained. This may be explained on the basis that citric acid, extracts from certain soils, phosphates in organic combinations that are not precipitated by ammonium molybdate, and that the presence of the undecomposed soluble silicates may hold by absorption the phosphate ions in solution.

Our second attempt was to destroy the organic and silicate compounds by evaporation almost to dryness, with aqua regia. The residue was taken with a few ec of aqua regia, diluted with water, and filtered. Phosphoric acid was determined in the filtrate by the official molybdate volumetric method. Although our results checked much better with those obtained by the Dyer modified method we were unable to obtain the ammonium phosphomolybdate precipitate in several of the treated extracts. It seems that the aqua regia treatment was not drastic enough, in some cases, to decompose some of the silicates that would tend to establish a competition for the adsorption of the phosphate ions in solution.

Our next procedure was then to evaporate the citric acid extracts to dryness with aqua regia and ignite the residue at low temperature to destroy the undecomposed organic matter and complete the dehydration and destruction of silicates. This treatment served as a basis for our recommended procedure (see pp. 288-289). Analytical results are expressed in Table II.

\section{Analytical Results of Perchat $\mathrm{P}_{2} \mathrm{O}_{5}$ by our Short Procedure}

All analyses by both methods were performed in the same extraction. The letters $A$ and $B$ following a sample number represent duplicate extractions. All the analyses by Dyer's modified method and by our short procedure in samples 18,20 and 23-27 inclusive, were made by the same chemist, F. A. Villamil. All other analyses by our short procedure were made by the senior author. The values in columns $A$ and $B$ represent percent $\mathrm{P}_{2} \mathrm{O}_{5}$ obtained respectively by the Dyer modified method and by our short procedure. The values of column $A-B$ are obtained by subtracting the values of column $B$ from those of $A$. The values $D$ represent the mean deviations. The number of determinations $n=45$. The value $Z$ represents the ratio of the mean of columns (A-B) to the square root of the mean of the values $\mathrm{D}^{2}$. The statistical interpretation of the results were obtained with values $\mathrm{Z}$ and $\mathrm{n}$ in the Student's table modified by Love (9). 
TABLE II.

COMPARATIVE VALUES BY STUDENT'S METHOD OF PERCENT $\mathrm{P}_{2} \mathrm{O}_{3}$ AS DETERMINED BY THE DYER MODIEIEU MELHOD AND OUR SHORT PROCEDURE

\begin{tabular}{|c|c|c|c|c|c|}
\hline No. & $\begin{array}{c}\text { Dyer's } \\
\text { of }{\stackrel{\mathrm{P}}{\mathrm{z}} \mathrm{O}_{5}}^{2}\end{array}$ & $\begin{array}{c}\text { Short } \\
\text { Procedure } \\
{ }_{\%} \mathrm{P}_{2} \mathrm{O}_{6}\end{array}$ & $A-B$ & $\underset{(A-B-.0003)}{\mathrm{D}}$ & $D ?$ \\
\hline 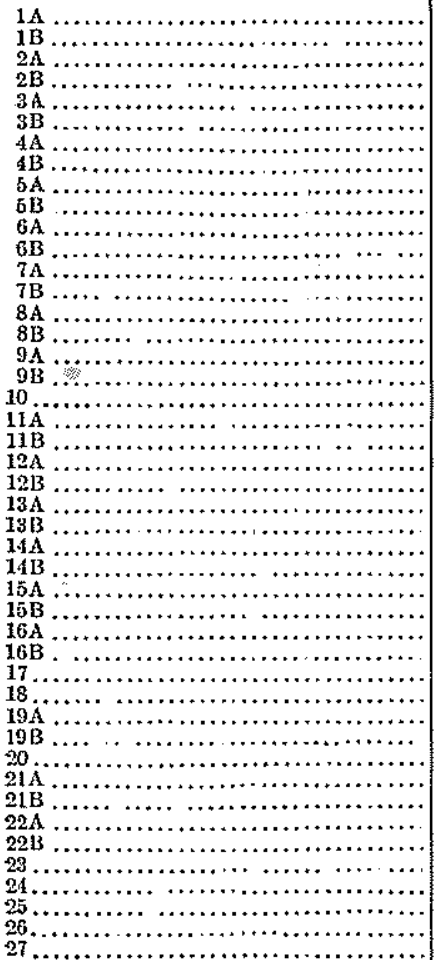 & $\begin{array}{l}.014 \\
.014 \\
.010 \\
.010 \\
.003 \\
.003 \\
.007 \\
.007 \\
.013 \\
.013 \\
.005 \\
.004 \\
.002 \\
.002 \\
.017 \\
.015 \\
.006 \\
.007 \\
.018 \\
.036 \\
.036 \\
.146 \\
.145 \\
.023 \\
.023 \\
.013 \\
.013 \\
.019 \\
.019 \\
.023 \\
.024 \\
.003 \\
.023 \\
.052 \\
.051 \\
.033 \\
.09 \\
.018 \\
.005 \\
.007 \\
.004 \\
.008 \\
.007 \\
.002 \\
.004\end{array}$ & $\begin{array}{l}.016 \\
.015 \\
.009 \\
.009 \\
.003 \\
.003 \\
.007 \\
.007 \\
.011 \\
.010 \\
.005 \\
.006 \\
.001 \\
.005 \\
.017 \\
.017 \\
.008 \\
.006 \\
.017 \\
.039 \\
.089 \\
.148 \\
.155 \\
.015 \\
.014 \\
.013 \\
.013 \\
.016 \\
.016 \\
.025 \\
.025 \\
.002 \\
.020 \\
.054 \\
.058 \\
.038 \\
.013 \\
.013 \\
.004 \\
.004 \\
.011 \\
.005 \\
.005 \\
.001 \\
.002\end{array}$ & $\begin{array}{c}-.002 \\
-.001 \\
.001 \\
.001 \\
0 \\
0 \\
0 \\
0 \\
.002 \\
.003 \\
0 \\
-.002 \\
-.002 \\
-.003 \\
0 \\
-.002 \\
-.003 \\
.001 \\
.001 \\
.003 \\
-.003 \\
-.002 \\
-.010 \\
.008 \\
.009 \\
0 \\
0 \\
.003 \\
.003 \\
-.002 \\
-.002 \\
.001 \\
.003 \\
-.002 \\
-.002 \\
-.005 \\
+06 \\
.005 \\
.001 \\
.002 \\
.003 \\
.003 \\
.01+2 \\
.001 \\
.002\end{array}$ & $\begin{array}{r}-.0023 \\
.0013 \\
.0007 \\
.0007 \\
-.0003 \\
-.0003 \\
-.0003 \\
-.0003 \\
.0017 \\
.0027 \\
-.0003 \\
-.0023 \\
-.0023 \\
-.0033 \\
-.0003 \\
-.0023 \\
-.0023 \\
.0007 \\
.0007 \\
-.0033 \\
-.0033 \\
-.0023 \\
-.0103 \\
.0077 \\
.0687 \\
-.0003 \\
-.01018 \\
.0027 \\
.0027 \\
-.0028 \\
-.10023 \\
.0007 \\
.0027 \\
-.0023 \\
-.0023 \\
-.0053 \\
.0037 \\
.0047 \\
.0007 \\
.0017 \\
.0027 \\
.0027 \\
.0017 \\
.0007 \\
.0017\end{array}$ & $\begin{array}{l}.0 .000529 \\
.00000169 \\
.00000049 \\
.00000049 \\
.00000009 \\
.00000409 \\
.00000009 \\
.00000009 \\
.00000289 \\
.00000729 \\
.00000009 \\
.00000529 \\
.00000529 \\
.00001089 \\
.000004 .09 \\
.00000529 \\
.00000529 \\
.00000019 \\
.00000049 \\
.00001089 \\
.00001089 \\
.00000529 \\
.00010609 \\
.00005929 \\
.000117569 \\
.00000009 \\
.04000009 \\
.00000729 \\
.00000729 \\
.00001529 \\
.00000529 \\
.00000049 \\
.00000729 \\
.00000529 \\
.00000599 \\
.00002809 \\
.00003249 \\
.00002209 \\
.00000049 \\
.00000289 \\
.00000729 \\
.00000729 \\
.00000 \% 199 \\
.00000049 \\
.00000289\end{array}$ \\
\hline 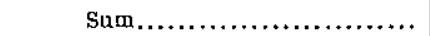 & .924 & .908 & .016 & & .00047045 \\
\hline Megn $\ldots \ldots \ldots \ldots \ldots \ldots$ & $.020 \bar{z}$ & .0202 & .0008 & & .0000105 \\
\hline
\end{tabular}

$$
z=\frac{.0003}{\sqrt{.0000105}}=.09
$$

Odds: Below 3:1

When both methods are statistically compared, $\mathrm{Z}=.09$ and the odds from the table (9) are found to be below $3: 1$. The odds indicate that there is no significant difference between the analytical results obtained by both methods.

That either method is as good as the other is corroborated by the excellent checks of the duplicates in different extractions.

Chances for personal analytical error are much less in the short 
procedure since the work is greatly facilitated by the elimination of the cumbersome procedure required for precipitation of $\mathrm{Fe}, \mathrm{Al}$, Ti and $\mathrm{P}_{2} \mathrm{O}_{5}$ with $\mathrm{NH}_{4} \mathrm{OH}$ in the Dyer modified method. The former method saves about 30 per cent of the time required by the latter.

\section{PoTASH}

Several modifications for the Dyer modified method were tried. Our results were unsatisfactory. We recommend the Dyer modified method with the following modification: Precipitate the lime together with the iro nand phosphoric acid. (See pp. 289-290).

Through the courtesy of Dr. W. W. G. Moir, agricultural technologist of the American Factors, Limited, Hawaii, and L. E. Davis, associate chemist of the Experiment Station of the Hawaiian Sugar Planter's' Association, we obtained a reprint of Gow's (7) work on a rapid colorimetric method for the determination of potash. "This method consists essentially of precipitating potassium chloroplatinate by means of its insolubility in alcohol, dissolving the precipitate in water and developing a color by the addition of stannous chloride. The intensity of the yellow color thus produced is directly proportional to the amount of platinum present in the precipitate and hence to the amount of potash present."

\section{SUMLMARX}

Research was undertaken with the purpose of shortening time without affecting accuracy of the Dyer modified method for the determination in soils, of phosphoric acid, lime and potash soluble in 1 per cent citric acid solution.

A short method is recommended for the lime determination based on the Chapman's method (4) for the precipitation of calcium oxalate in acid solutions ( $\mathrm{pH}$ 3.9-4.2) in the presence of iron, aluminum, titanium, manganese, magnesium and phosphates. A short method is recommended for the phosphoric acid determination. Results are analyzed statistically by Student's method. Several of the colorimetxic methods recommended for the phosphoric acid determination are also discussed.

\section{ACKNOWLEDGMENTS}

The authors wish to express their acknowledgments to Mr. F. A. López Dominguez, Director of the Insular Experiment Station for valuable suggestions after reading the manuscript; to Mr. Bernardo 
G. Capó, analytical chemist for the fertilizer control laboratory of the Department of Agriculture and Commerce and to Mr. Fernando Chardón, tobacco specialist of the Phytotecnics Division, Insular Experiment Station for valuable suggestions relative to the statistical interpretation of the chemical data, and to Dr. W. W. G. Moir, agricultural technologist of the American Factors, Limited, Hawaii and L. E. Davis, associate chemist of the Experiment Station of the Hawaiian Sugar Planter's' Association for their courtesy in sending reprints of references (7) and (10), and for the proper citation of reference (3) which we requested after being unable to obtain the bulletin referred.

\section{Bublography}

(1) Arrhenius, 0. Fosfaat bepalling met de molybdeen-blauwmethode. (Phosphate determination with the molybdicblue method). Archief Suikerindus Ned-Indie, 35(2): 903909. 1927.

(2) Bell, Doisy \& Briggs. Determination of phosphorus in urine and blood. In John H. Yoe's Photometric Chemical Analysis, Vol. I, Colorimetry. Pp. 346-348. John Wiley \& Sons, Inc., N. Y. 1928.

(3) Burgess, P. S. A study of the principal plantation soil types as found on the island of Hawaii. (Dyer's modified method.) H. S. P. A. Agr. \& Chem. Bull. 45:94. 1917.

(4) Chapman, H. D. The precipitation of calcium oxalate in the presence of iron, aluminum, titanium, manganese, magnesium, and phosphates, with special reference to the determination of total soil calcium. Soil Sci. 26:479-486. 1928.

(5) Deniges, G. (An extremely sensitive reaction of phosphates and arsenates and its application.) Compt. Rend. 171: 802-804. 1920.

(6) Fiske, C. H., \& Subbarow, Y. The colorimetric determination of phosphorus, Jour. Biol. Chem. 66:375-400. 1925.

(7) Gow, Paul L. A rapid method for the determination of potash. 'The Hawaiian Planters' Rec. 35:401-409. 1931.

(8) Lonstein, Ida. Rapid colorimetric determination of phosphorous in soils and vegetation. Afric. Jour. of Sc. 23: 188-195. 1926.

(9) Love, H. H. A modification of Student's table for use in interpreting experimental results. Jour. Amer. Soe. Agron. 16: $68-73.1924$. 
300 THE JOURNAL OF THE DEPARTMENT OF AGRICULTURE OF P. R.

(10) Ward Ritchie R. The colorimetric determination of phosphorus in citric acid extracts of soils. Soil Sci. 35:85-97. 1933.

(11) Warren, R. G., \& Pugh, A. J. The colorimetric determination of phosphoric acid in hydrochloric acid and citric extracts of soils. Jour. Agr. Sc. 20:532-540. 1930.

(12) Yoe, John H. Photometric chemical analysis. Vol. I. Colorimetry. (Beer's law) Chap. IV. Colorimeter calibration and correction curves, pp. 70-82; Chap. V. Errors in colorimetry p. 88. John Wiley \& Sons, Inc., New York. 1928. 